\title{
Zhao Jiping and the Sound of Resistance in Red Sorghum
}

\author{
Brian C. THOMPSON \\ The Chinese University of Hong Kong, Department of Music \\ 2/F, Hui Yeung Shing Building, Shatin, NT, Hong Kong, China \\ E-mail: thompson@cuhk.edu.hk
}

(Received: April 2015; accepted: June 2015)

\begin{abstract}
Since seizing power in 1949, China's Communist Party has exerted firm control over all aspects of cultural expression. This policy took its most radical turn in the mid-1960s when Mao Zedong launched the Cultural Revolution (1966-1976), aiming to rid the country of bourgeois elements. The composer Zhao Jiping was a student at the Xi'an Conservatory during this period. He graduated in 1970, but was able to continue his studies only when the Central Conservatory reopened in 1978. On completing his studies, he established himself as a composer of folk-inspired music for film and the concert stage. This paper focuses on Zhao's score for director Zhang Yimou's Red Sorghum (Hong gao liang, 1987), a film based on the 1986 novel by 2012 Nobel laureate Mo Yan. While the composer enjoyed only limited recognition beyond China, he went on to score other successful films, among them Raise the Red Lantern (1991) and Farewell, My Concubine (1993), and achieve success as a composer of concert music. The paper connects Zhao's musical language to the impact of the Cultural Revolution by examining how in Red Sorghum his music was employed to evoke a virile image of rural China.
\end{abstract}

Keywords: Chinese music, Chinese film, Zhang Yimou, Zhao Jiping, Second SinoJapanese War, Mo Yan

In the seven decades since the end of the Second Sino-Japanese War, the Communist Party of China (CPC) has made effective use of military might and propaganda to defeat its rivals and maintain its grip on power. As in other communist states, the CPC has relied on culture and artists to serve political purposes. Even since the 1980s, when China began to open its economy to the outside world, periods of artistic freedom have been the exception. More than any Chinese leader in decades, 
the current president, Xi Jinping, has made it clear that he sees the role of the arts as serving political ends. Speaking to a gathering of artists in October 2014, Xi reminded his listeners that "cultural and artistic sectors in China must serve the people and socialism." Chinese artists, he asserted, should create works that "disseminate contemporary Chinese values, embody Chinese traditional culture and reflect [the] Chinese people's aesthetic pursuit[s]." To the president the purpose of a work of art is clear, it should "present patriotism as the main theme and foster correct viewpoints of history, nationality and culture, as well as strengthen pride in being Chinese." President Xi made these comments with the intention of drawing comparisons to those expounded by Chairman Mao in the 1940s. Xi's comments were directed mostly towards the visual arts and intended as a rebuke of the hypermaterialism of contemporary China. They were also a reminder that since taking power in 1949, the CPC has maintained firm control over artistic expression in China. ${ }^{2}$

It was in the decade following Mao's death, in 1976, that China's Fifth Generation of filmmakers began to emerge. The 1980s was a time of market reforms and of China's opening up to the world culturally. Among the films of the 1980s, Red Sorghum was to achieve international acclaim. ${ }^{3}$ It signalled the arrival of Gong $\mathrm{Li}$ as China's leading actress, and the beginning of Zhang Yimou's career as China's preeminent director. Zhang was by this time already in his mid-thirties, his career having been postponed by the Cultural Revolution. The same was true of the composer of the film's music, Zhao Jiping, who had been able to complete his studies only after Mao's death. His career as a film composer had begun in 1984, when he wrote the music for the first film of director Chen Kaige, Yellow Earth. ${ }^{4}$ With the score for Red Sorghum, he would become widely known in China.

Red Sorghum was based on the first novel of Zhang and Zhao's contemporary, Mo Yan, a writer who would go on to win the 2012 Nobel Prize for literature. The events of his novel take place over a period of fifty-three years, between 1923 and 1976, but are set largely in the 1920s and 1930s, during the Chinese Civil War and the Second Sino-Japanese War. The central characters are the narrator's grand-

1. 'China's Xi Points Way for Arts,' China Daily, 16 October 2014. chinadaily.com; the BBC reported on Xi's comments in "Chinese President Xi Jinping Warns Against 'Immoral' Art," 16 October 2014 (http://www. bbc.com/news/entertainment-arts-29645574). Bloomberg Businessweek quoted Xi as saying that "socialist culture and art is, in essence, the culture and art of the people," and that artists should not "go astray while answering the question of whom to serve, otherwise their works will lack vitality." Xi also warned that "artworks must not be the 'slaves' of the market and should not bear 'the stench of money." Dexter Roberts, "Echoing Mao, China's Xi Says Art Must Serve the People and the Socialist Cause," Bloomberg Businessweek, 16 October 2014. http://www.businessweek.com/articles/2014-10-16/chinas-xi-to-artists-follow-the-party-line

2. President Xi's immediate predecessors, Hu Jintao (2002-2012) and Jiang Zemin (1989-2002), took a light hand on the arts when compared with the previous leaders.

3. Red Sorghum won many prizes at China's Golden Rooster Awards in 1988, including the prize for the best original score, but it was after winning the Golden Bear at the 1988 Berlin International Film Festival that the film received international attention and wide distribution.

4. For a discussion of the music in Yellow Earth, see Sue Tuohy, "The Social Life of Genre: The Dynamics of Folksong in China," Asian Music 30/2 (Spring-Summer, 1999), 39-86. 
parents, who run a distillery in northeast China. As the dominant crop in this region and the main ingredient of the local wine, the sorghum itself establishes the setting. Much of the novel's action takes place within the fields of sorghum, including the central event of the novel, the battle at Black Water Bridge, in which the villagers staged a legendary assault on a Japanese convoy. Part of the novel's success lies in its author's willingness to discuss China's disjointed efforts to repel the Japanese, and in his choice of highly unusual protagonists. As literary critic Shelly W. Chan has noted, members of the CPC were the usual leaders in literary works published in China from 1949 to the 1980s. In Mo Yan's novel, it is an unruly group of peasants (murderers and bandits among them) who are the heroes. ${ }^{5}$ Kenny Kwok-kwan $\mathrm{Ng}$ has argued that this celebration of the anti-hero reflected the class struggles having taken place in the 1970 s and after. ${ }^{6}$ In Red Sorghum, the crop's rich colour functions as a symbol for the blood that is shed in those fields but also for the vitality of the region's inhabitants. The crop's loss of colour by the 1970s thus serves as a metaphor for both the relative peace in that time and for societal decline under communist rule, where bureaucracy has replaced initiative.

The story was modified in a number of ways in its adaptation for the screen in the mid-1980s. The narrator introduces the characters at the start of the film, as in the novel, but the action is restricted to the 1920s and 1930s. Whereas the novel shifts back and forth in time, Zhang's film has a much more linear structure. The first part deals with the main characters' relationship and personal struggles. The second part begins abruptly, about two-thirds of the way through, with the arrival of the Japanese. The film then culminates in the Battle of Black Water Bridge. Unlike the novel, the film eschews direct references to the Civil War. The plot only becomes overtly political as the Japanese enter the story. At this point, there is a significant change in the role of one character, "Arhat" Liu, who is tortured and killed by the Japanese. In the novel, he is simply a distillery worker angered by having been forced to work by the Japanese. In the film, he is killed seemingly because he had been working as a recruiter for the communists. His death drives the story to its dénouement.

The music heard in Red Sorghum is rooted in the composer's experience and it is authentic to the extent that it is scored for instruments commonly used in peasant rituals in northeast China and in that it conforms generally to the song forms of the region. These aspects of Zhao's score have been the subject of several articles by Chinese writers. Tong Min Fan has used the example of Red Sorghum to argue in favour of the use of folk music in film. ${ }^{7}$ Writers such as Li Qiang and

5. Shelly W. Chan, A Subversive Voice in China: The Fictional World of Mo Yan (Amherst, N.Y.: Cambria Press, 2011), 28.

6. Kenny Kwok-kwan Ng, “Toward an Allegorical Interpretation: Myth and Class Fantasy in Mo Yan's Red Sorghum," Tamkang Review, 27/3 (1997), 343-381.

7. Tong Min Fan, "Yi dian ying 'Hong Gao Liang' wei li, lun min ge zai dian ying zhong de zuo yong" [Using Red Sorghum as an example to discuss the functions of folk songs in movies], Northern Music (August 2013), 142-143. 
Wu Jun-ting have described the songs performed on screen and the origins of their style in traditional music, but fail to discuss how the music functions within the structure of the film. ${ }^{8}$ In this article, I explore how Zhao Jiping's score uses these forms, initially in on-screen performances, and subsequently in non-diegetic recapitulations, to reinforce the film's theme of peasant resistance.

\section{Performances: on screen and imagined}

As the film opens, the narrator's grandmother, sixteen-year-old Dai Fenglian, is being married off to a wealthy wine maker, three times her age and suffering from leprosy. She is conveyed to her new home in a traditional sedan, carried by four burly young men, and accompanied by a group of musicians. Not long into the journey, the leader, Yu Zhan'ao, later the narrator's grandfather, decides to "bounce the piss out of her," and they break into what is, at least from their perspective, the humorous "Jolting the Chair Song." The lyrics, describing a young groom's dismay on seeing his new wife for the first time, were written by director Zhang Yimou. ${ }^{9}$

"Jolting the Chair Song" (words by Zhang Yimou)

The guests haven't gone yet,

But the groom has disappeared,

He can't wait any longer,

He's gone off to lift the veil

Oh, my darling. Oh, my darling

Look at her pock-marked face

Flat-nosed, hair-lipped, eyelids inside out,
A chicken neck, an ugly face

A head crawling with lots of lice Oh, my darling. Oh, my darling

Oh, dear. What an ugly bride

She wants to hug me, hug me I turn and run. I can't look

I'd rather sleep in the pigsty

Oh, my darling. Oh, my darling.

With a melody that hovers around the home pitch of D, the sedan bearers' emphasize the duple meter with their bouncing movements, accompanied on screen by percussion, suonas, and a zheng (Example 1). In the novel, Mo Yan refers to the suona with a generic term for bugle or horn $(l a b a)$. The tenor suona is used to signal the start of the song (Plate la-b).

The scene ends when Yu hears Dai weeping and signals his associates to stop the song and continue the journey. After this show of compassion, in the next

8. Li Qiang, "Zhao Jiping dian ying yin yue chuang zuo yuan su jie xi” [An analysis of Zhao Jiping's film music creation], Contemporary Cinema, 3 (2011), 158-160; Wu Jun-ting, "Nong bi zhong cai zhong de 'yang gang' ji diao - Zhao Ji-ping 'Hong Gao Liang' pei yue zai xing xiang”' [The 'masculine' tone in a colouristic work - a revisit of Zhao Jiping's music production in Red Sorghum], Mang Zhong, 3 (2013), 154-155.

9. Jiao Xionping, "Discussing Red Sorghum," in Zhang Yimou: Interviews, ed. Francis K. Gateward (Jackson: University Press of Mississippi Press, 2001), 14. 
Example 1 Opening measures of the "Jolting the Chair Song"
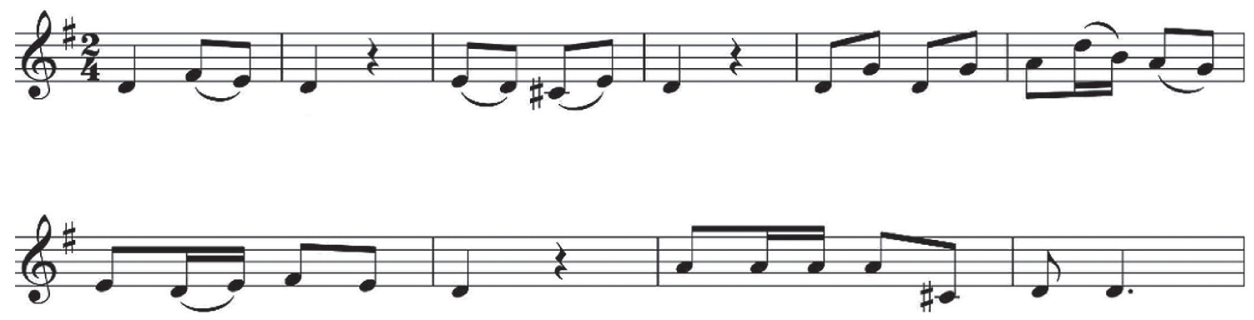

Plate 1a-b Musicians and sedan bearers performing the "Jolting the Chair Song"
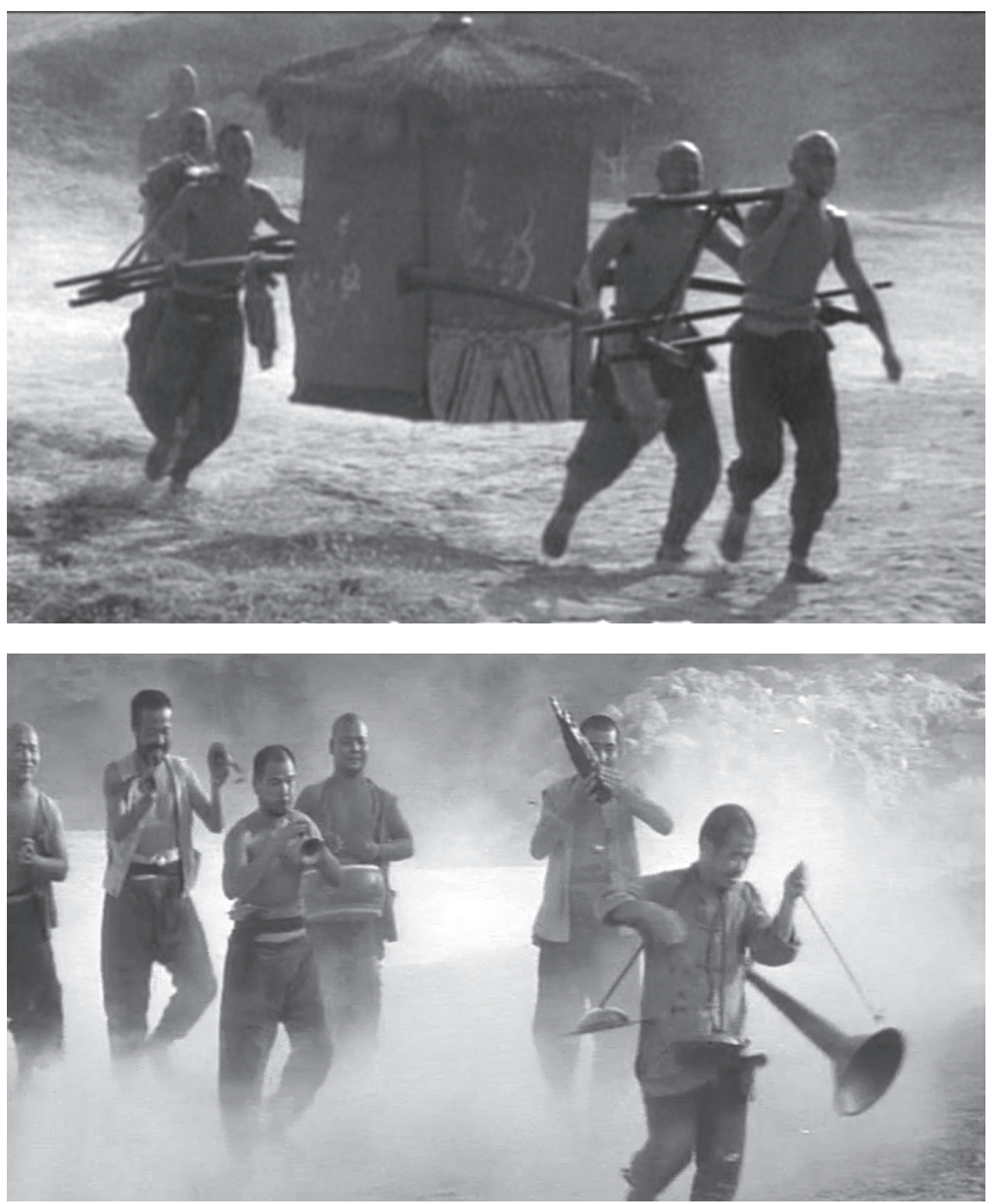

Studia Musicologica 56, 2015 
scene $\mathrm{Yu}$ demonstrates his bravery by attacking an armed bandit who is about to kidnap the young bride. Together the musicians and sedan bearers beat the man to death. Here, as elsewhere, the violence in the film is less graphic than in the novel, where the killing blow comes from a bugle buried in the man's skull. ${ }^{10}$

Two important musical sequences take place about 10 minutes further into the film, when, three days after her marriage, Dai returns home to visit her parents. En route, Yu pulls her from her donkey and chases her deep into the field. There, he tramps down a bed of sorghum upon which he places the young woman, who signals her willingness with a nod. The sex act is neither seen nor heard. As we see the sorghum tremble, Zhao fills the soundtrack with a wild chorus of thirty suonas, four shengs, and one large drum. ${ }^{11}$

As Dai resumes her journey, Yu sings to her unseen from within the sorghum. The words to this seemingly improvised song, composed by Zhao, come directly from the novel (Example 2).

Example 2 Opening measures of "Little Sister, Boldly You Move On"
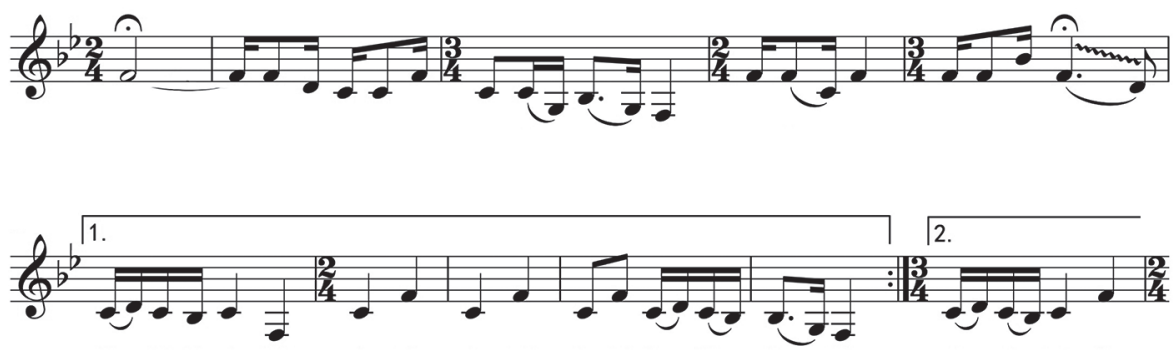

"Little Sister, Boldly You Move On" (words by Mo Yan)

Little sister, boldly you move on

Your jaw set like a steel trap

Bones as hard as cast bronze

From high atop the embroidery tow

You toss down the embroidered ball

Striking me on the head

Now join me in a toast with dark-red sorghum wine. ${ }^{12}$

10. Mo Yan, Red Sorghum, translated by Howard Goldblatt (London: Arrow Books), 52.

11. Li Hong-bo, "Qian tan Zhao Jiping ying shi yin yue de min zu qing jie" [On Zhao Ji-Ping's ethnic affinity in film music], Movie Review, 2008 (2), 38-39.

12. Mo Yan, Red Sorghum, 97. 
Yu's song causes Dai's father, drunk and ambling along the path on foot, to curse the singer and demand he show himself. Soon after this scene, Yu murders the distillery owner. He does this to clear the way for himself to become Dai's husband, but for a time she spurns him, as she takes over the management of the distillery. ${ }^{13}$ It is there that we hear the next vocal performance, as Dai witnesses the new wine being made. After producing the new wine, the workers, led by the foreman Uncle "Arhat" Liu, face the camera, looking up to a shrine, raise their bowls and sing to the God of Wine (jiu shen qu) (Plate 2). The chant-like opening quickly gives way to another full-throated performance.

Plate 2 "Arhat" Liu leads in the singing of "The Music of the God of Wine"

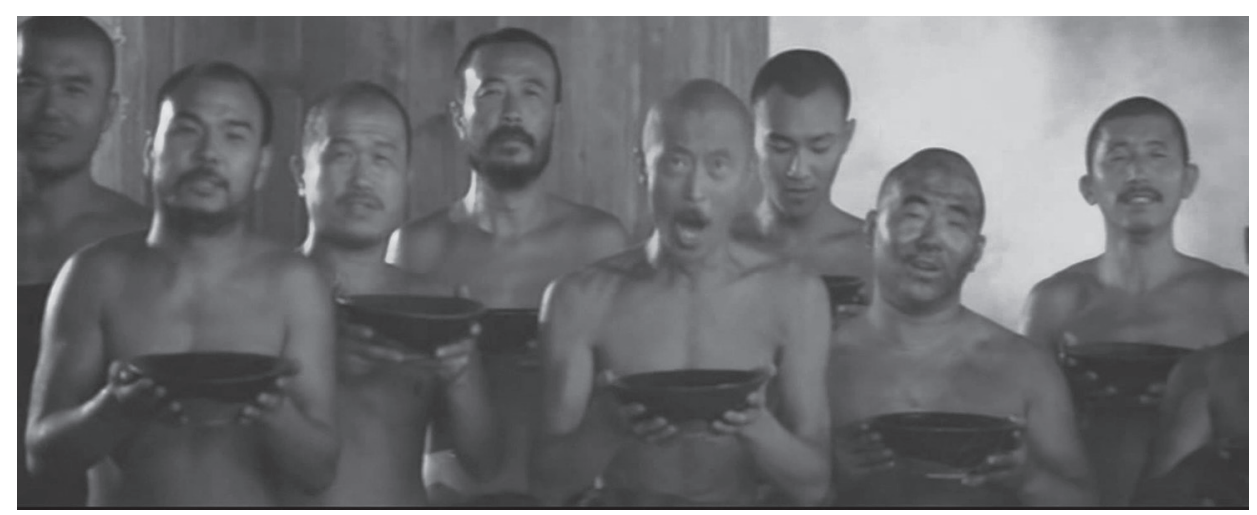

"The Music of the God of Wine" (words by Zhang Yimou)

If you drink our wine,

You'll breathe well and you won't cough;

If you drink our wine,

You'll be well and your breath won't smell bad;

If you drink our wine,

You won't kowtow to the emperor.

At the conclusion of the song, the men drink greedily, and finish the rite by smashing their clay bowls in celebration of the completion of the new batch of the life-affirming drink (Example 3). Unlike the previous songs, this one does not appear in the novel. The words and music are entirely the invention of the filmmakers, Zhang and Zhao, respectively. The song is at once comic and reverential. It is also political, as, they claim, the wine gives one the courage not to "kowtow

13. The murders are not shown in the film but are described in detail in the novel. 
Example 3 The refrain of "The Music of the God of Wine"

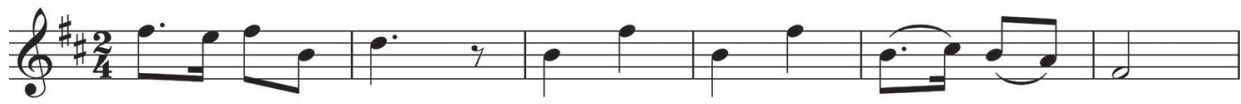

to the emperor." The refrain is similar in its phrase structure and intervals to the "Jolting the Chair Song." The rising perfect fourths (also prominent in "Little Sister") are replaced here by perfect fifths, and the rhythms are augmented (as in "Little Sister").

The happy scene provides a sharp contrast for subsequent events. Whereas the war is the focus of the story from the start of the novel, there is no direct mention of it until late in the film. After the blessing of the new wine, "Arhat" Liu leaves the village and as the next scene opens nine years have passed and the distillery is thriving. The Japanese then appear, building a highway with forced labour and terrorising the Chinese. Liu has been captured and is skinned alive in front of the villagers.

From the sorghum field in which Liu has been tortured and killed, the scene cuts back to the distillery that same night. Fires are burning and reflected in the eyes of the enraged Dai. She pours wine for herself and Douguan, her son, then challenges the men to "drink up" and avenge "Brother Liu." Yu pours a bowl of wine for himself and for each man, sets them alight, and leads the workers in another performance of the "Music for the God of Wine," once again facing the camera as they sing. Although the words are the same, through the vehemence of the performance, the singers transform the music into a war song (Plate 3).

The next morning Yu leads the assault on the Japanese. In the novel, Commander $\mathrm{Yu}$ leads his troops in what is a battle lasting much of a day. The events shown in this scene of the film condense the action down to a few minutes and a single assault. As the scene opens, Dai has prepared a meal and is awaiting the return of the men. She decides to deliver the food and sets out briskly along the path. Douguan calls to her and she smiles as she walks. The only other sounds are those of footsteps on the path and the wind rustling the sorghum. The scene cuts back to Douguan, who hears the approaching vehicles and calls out to his mother. As he does, a machine-gun mounted on a truck is seen in a close-up. It begins firing, its clatter heard full-volume against the boy's shouts. The scene cuts to waiting men who now begin their ambush. When one of their improvised canons explodes and another fails, they rush the convoy. In a close-up, the suona player seen earlier in the film signals the attack, and they charge, armed with Molotov cocktails made with sorghum wine (Plate 4). At this moment, the action shifts to slow motion, effectively conveying what might be described as a suspension of time within Mo Yan's prose. As it does, an instrumental version of the "Jolting the Chair Song" 
Plate 3 Commander Yu leads a reinterpretation of "The Music of the God of Wine"

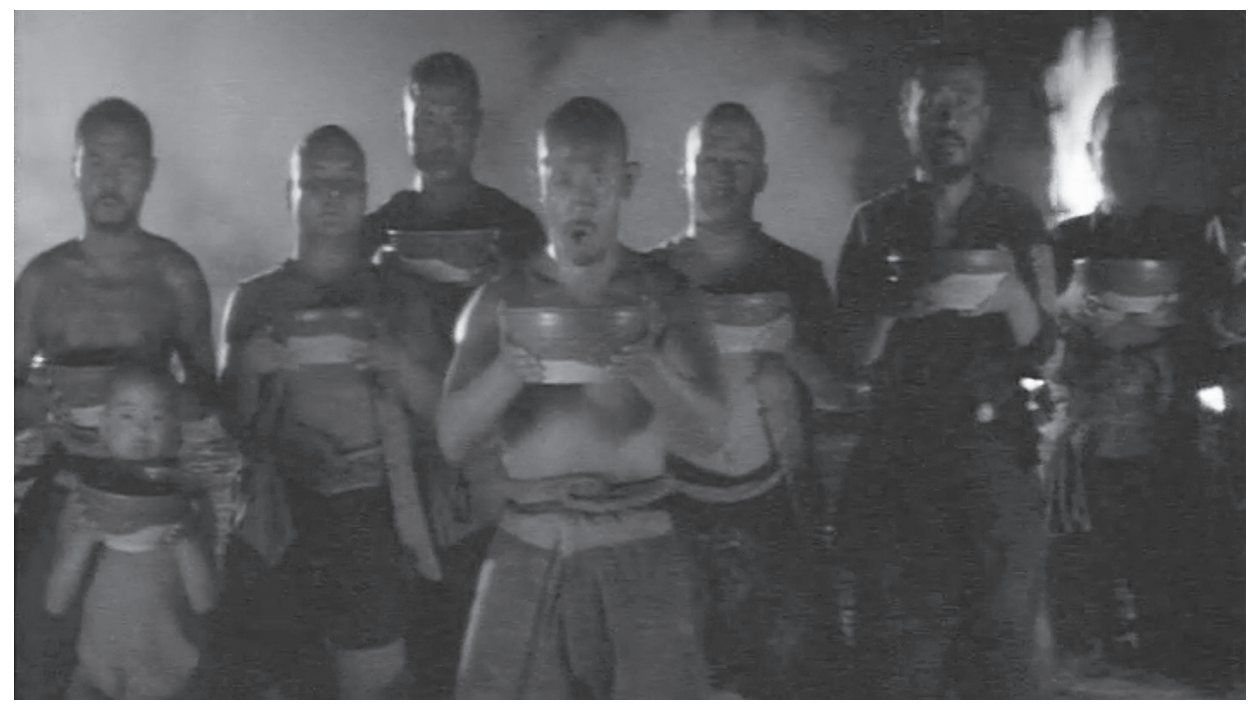

Plate 4 "Bugler" Liu signals the attack on the Japanese convoy

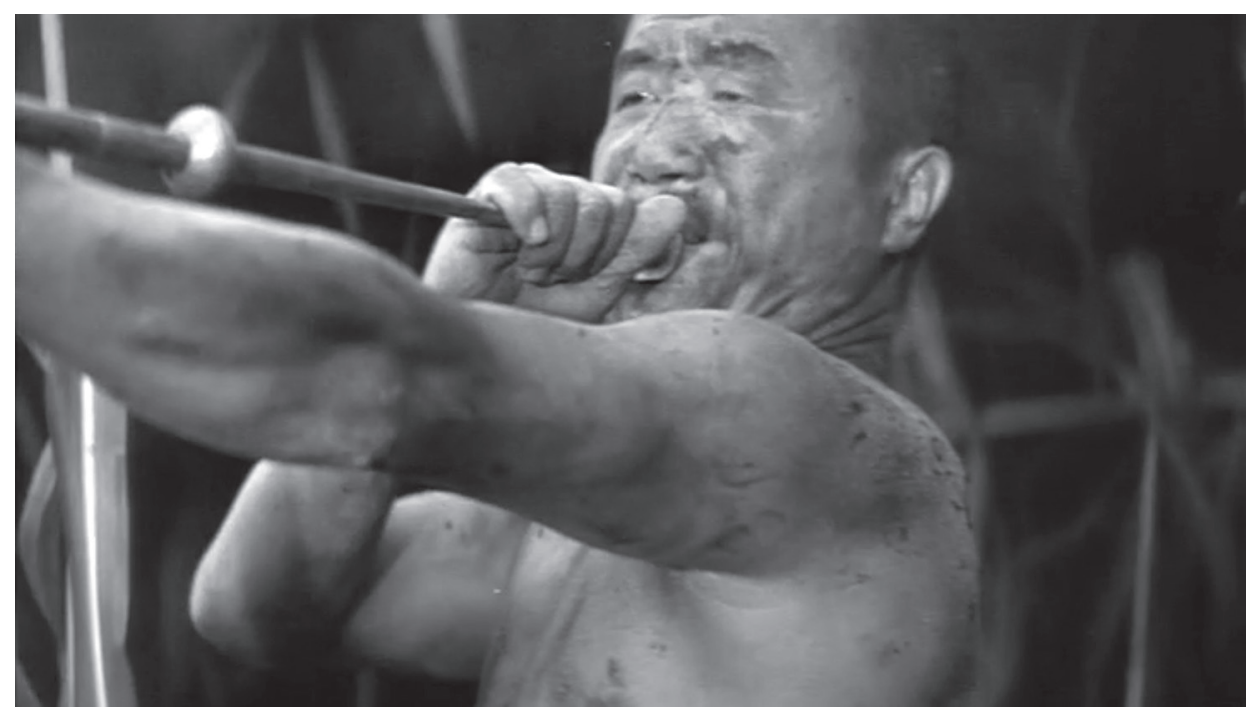

rises from the din. The scene cuts back to Dai, arms spread across the screen like a crucified Christ, falling, then back to the peasant soldiers, and the scene culminates in a single explosion that ends in silence. 


\section{Music, tradition, and identity}

Up to this point, most of Zhao's music in the film had been performed on screen. The climactic scene begins a more poetic reinterpretation of the music previously heard. After the explosion, it is through music and visual images that Yu re-lives the events of his life in his mind as he stands over the body of his dead wife. The camera focuses on his blackened face and as the scene cuts to his thoughts of the past we hear, as though in the distance, his love song, "Little Sister," combined with the rustling sorghum. His song echoes quietly as the camera returns to his face and the sky. An eclipse of the sun takes place (symbolic of the costly defeat of the Japanese, perhaps) and as it does, the images on screen turn a deeper red and Douguan breaks into a wild re-interpretation of Yu's "Little Sister":

Mom, Mom goes to the southwest

On a wide road, by a long beautiful boat,

Mom, Mom goes to the southwest

On a big horse with enough expenses

Mom, Mom goes to the southwest

Settle down in a good place and beg alms in a bad situation.

As he sings, his voice gradually fades and a drum enters with a slow, steady beat, before the wild suonas of the sex scene enter and the closing titles appear on screen.

Mo Yan's novel provided the filmmakers with many of the basic ideas for the use of music. Apart from diegetic performances described in the novel ("Jolting the Chair Song" and "Little Sister"), the film draws on several references to music and musicians. These include the scene described above, where the musicians participate in the killing of the bandit. Among the others are several scenes drawing attention to the character known as "Bugler" Liu. Just before leading the assault on the convoy, for example, Commander Yu instructs the bugler to "sound your horn for all you're worth," as soon as they start firing..$^{14}$ Later, the narrator says, "the long, sorrowful blast of a bugle near the bridge is immediately followed by the staccato rhythm of machine-gun fire." 15

The music heard in the sex scene and again in the closing titles is one Zhao Jiping's most creative imaginings from Mo Yan's novel, and a necessary one, given the restrictions on what could be shown or heard in a Chinese film. The music appears to have been inspired by the ambush scene described in the novel and the

14. Mo Yan, Red Sorghum, 27.

15. Ibid., 74. 
passage in which Dai, lying on the ground after being shot, "sees a multi-coloured ray of light streaming from above, and hears heaven's solemn music, played by horns and woodwinds, large and small." When her son runs off to find help, the sound of his "retreating steps" turn into "a gentle monologue, then in the music from heaven that [she] had heard a moment earlier. It is the music of the universe, and it emanates from the red sorghum." ${ }^{\prime 6}$ As the instrumental music of the sex scene returns in the closing credits, it speaks directly to the listener, recalling the passion of the earlier scene and the intensity with which Dai and Yu lived, and locating of the source of their identity in the land.

Zhao's rise as a de facto national composer of the 1980s reflected the politics of the time. Several decades earlier, Chinese nationalists had sought to create a repertoire along Soviet or European models. ${ }^{17}$ The class conflicts of the 1960 s and 1970s brought peasant music to the fore and Zhao was well equipped to supply what was asked of him. The style of music created for Red Sorghum continues to be described by many Mainland Chinese music scholars and journalists as the prototypical music of China, while other musical traditions, especially those associated with the bourgeoisie, have faced censure. ${ }^{18}$ Zhao's early film scores helped to fuel the popularity of this musical style. He followed Red Sorghum with the music for a number of films that also achieved both popular and critical success, among them three more collaborations with Zhang Yimou that feature Gong Li: Ju Dou (1990), Raise the Red Lantern (1991), and The Story of Qiu Ju (1992), and his music is frequently heard in concert. The critic Chow Fan-fu has even likened Zhao's music to that of Sergei Rachmaninov, in its ability to express the culture in which he has been raised. ${ }^{19}$ And yet, despite its popular success, little has been written about Zhao's music beyond journalistic reporting that speaks largely in generalities. Mainland-based scholars might not yet be prepared to question the politics of a music that enjoys both popular success and political support.

In China, where censorship was and remains firmly in place, the publication of Mo Yan's novel and the release of Zhang Yimou's film constitute a form of state endorsement. As in 1984's Yellow Earth, it presented an opportunity to celebrate traditional culture and especially one that reflected strength. Although China is rich in traditional musics, the reasons for privileging this form seems clear: it presents Chinese culture as robust, manly, and firmly rooted in the land. In its story, and music, Red Sorghum was a response to the many military humiliations China

16. Ibid., 76-77.

17. See, for example, Hon-Lun Yang, "The Making of a National Musical Icon: Xian Xinghai and His Yellow River Cantata," in Reading Chinese Music and Beyond, eds Joys H. Y. Cheung and King Chung Wong (Hong Kong: Chinese Civilisation Centre, City University of Hong Kong, 2011), 55-86.

18. See, for example, Bell Yung, "Music of Qin: From the Scholar's Study to the Concert Stage," in Reading Chinese Music and Beyond, 16-18.

19. Chow Fan-fu, "Visual Imagery of Sounds and the Culture Deep Within - The Making of the Charismatic Music of Zhao Jiping," in The Magical Music of Zhao Jiping, Concert programme booklet, Hong Kong Chinese Orchestra (10 May 2014), 24-25. 
suffered in the twentieth century. It is a phenomenon much like that observed by Annegret Fauser in her study of French music in the aftermath of the Franco-Prussian War - where state institutions attempted to purge music of feminine characteristics. ${ }^{20}$ In Red Sorghum, the masculine elements prevail in music that is loud, brash, and performed most often by bare-chested men. In the climactic scene, the Chinese arm themselves with tradition itself, "jolting" the invaders with bombs made of their local spirits, accompanied by a soundtrack rooted in folk tradition. Given the vagaries of China's domestic politics, the current president's disposition towards traditional culture, and the country's unresolved tensions with Japan, the world of Red Sorghum remains largely intact as the thirtieth anniversary of the film's release approaches. ${ }^{21}$

\section{Appendix \\ The main characters in Red Sorghum}

\begin{tabular}{|l|l|l|}
\hline Character & Description & Actor \\
\hline Dai Fenglian & $\begin{array}{l}\text { also known as “Grandma" and Jiu'er } \\
\text { ("Little Nine," as she was born on the 9 } \\
9^{\text {th }} \text { month) }\end{array}$ & Gong of the \\
\hline Yu Zhan'ao & $\begin{array}{l}\text { also as “Grandpa," and also referred } \\
\text { to as “Commander Yu" in the novel }\end{array}$ & Jiang Wen \\
\hline Douguan & Dai Fenglian's son, and the narrator's father & Liu Jia \\
\hline "Arhat" Liu & $\begin{array}{l}\text { the distillery foreman; in the novel, he is rumoured to } \\
\text { be the narrator's grandfather }\end{array}$ & Teng Rujun \\
\hline "Bugler" Liu Sishan & $\begin{array}{l}\text { a funeral and wedding musician; only referred to by } \\
\text { name in the novel }\end{array}$ & $\begin{array}{l}\text { actor's name } \\
\text { unknown }\end{array}$ \\
\hline
\end{tabular}

20. Annegret Fauser, "Gendering the Nations: The Ideologies of French Discourse on Music (1870-1914)," in Musical Constructions of Nationalism: Essays on the History and Ideology of European Musical Culture 1800-1945, eds Harry White and Michael Murphy (Cork, Ireland: University of Cork Press, 2001), 72-103.

21. In an essay exploring the roots of Chinese's identity, Peter Hays Gries discusses anger many Chinese feel towards Japan and disputes the widely held view that it is the CPC that shapes and exploits the people's animosity towards Japan: "China and Chinese Nationalism," in The Sage Handbook of Nations and Nationalism, eds Gerard Delanty and Drishan Kuman (London: Sage Publications, 2006), 489. 